\section{Research Article}

(C) 2021 M. P. Sebola.

This is an open access article licensed under the Creative Commons Attribution-NonCommercial 4.o International License

(https://creativecommons.org/licenses/by-nc/4.o/)

\title{
Peer Review Practices in Scientific Journals and Developmental Scholarship in South Africa: A Peer Reviewer Perspective
}

\author{
M. P. Sebola \\ University of South Africa, \\ Preller St, Muckleneuk, \\ Pretoria, ooo2, \\ South Africa
}

DOI: https://doi.org/10.36941/ajis-2021-0156

\section{Abstract}

\begin{abstract}
The development of science starts with investment in human capital development. Thus far arguments are that it is innovation and development of science which can assure the country of good economic, political and social development. A continuous investment in the youth in academia is a necessity to foster and continue the requirement and continuity of the development of science in academia to advance the society developmentally. This article is conceptual in approach and uses secondary literature to argue that the goal to pursue developmental scholarship, does not only lie with incapacity to mentor, but also lie with the complex peer review system which should enable the emerging researchers with an opportunity to enter the publication space. Therefore, the methodological perspective of the article is purely qualitative and based on scientific materials explored to answer the research question raised in the article. This article concludes that the goal of achieving the next generation of researchers in both academia and practice shall require a system which is highly developmental through a well-developed system of mentoring within the academic environment.
\end{abstract}

Keywords: Emerging researchers, Science, Scholarship, Peer review

\section{Introduction}

Peer review in the academic environment is done in scholarly areas such as published journal articles, book publications, post graduate research qualifications and grant proposals. The purpose is solely to ensure that the published or approved materials have passed a particular set of academic standards believed to be of integrity. Wilson (2012: 1) opined that over 1.5 million articles published annually in scientific journals are produced through a peer review system. For purposes of this article, the focus shall be on journal articles than on other forms of scientific publications. The question which I want us to look at in this article is: Is the peer review mechanism in scholarly journals capable of developing emerging researchers in the various fields of science to resolve the political, social and economic problems faced by the country? In addressing the research question the discussion will focus on the concept of Peer review in scientific journals, developmental scholarship and peer review effects as well as Good practices in Peer review. The methodological perspective of the article is purely qualitative and based on scientific materials explored to answer the research question raised in the article. 


\section{Peer Review in Scientific Journals}

Even though peer review in scientific journals is said to have evolved in the $18^{\text {th }}$ century (Kumar, 2009; Sebola, 2018) through the Journals, Journal des Scavans in France and Philosophical Transactions of the Royal Society of London, it is not known whether it emerged for all disciplines at the same time. Better to assume that all disciplines scientific journals may have learned to do peer review of their scholarly publications from the two journals. A view which I believe can be contested by many scholars from different angles if pursued further. Nevertheless, peer review in scientific journals remains an important yardstick to measure the quality of published scientific articles in modern scholarly space. Some authors view peer review as "the well-established means of evaluating the quality and relevance of research" (Butchard, Rowberry, Squires and Tasker (2017:6). Generally, peer review is defined as "an expert assessment of submitted materials with the goal of ensuring that valid article is accepted, the messy article improved, and the invalid article rejected" (Walker,2017). It is however that more often than not, such goals are not realised in scientific publications in which instance, more often messy and invalid articles are published as it is, while in some journals valid ones are rejected for differing perspectives with either editors or peer reviewers. We may acknowledge that editors and peer reviewers are human and have their own scholarship weaknesses and personal views about certain ideas held by others, which they may not subscribe to. Hence the rejection of certain scientific articles becomes unfair.

The rejection of a particular knowledge for publication happens when reviewers and editors are of the view that publishing such materials may pose scholarly risk in terms of both knowledge generation and quality of the produced knowledge. Maserumule (2012), opined that such knowledge which is not supposed to challenge the dominant paradigm, may be seen as little and posing danger to the dominant knowledge". An assumption which may rarely come from an editor as editors are believed to be practitioners and beneficiaries of such unspoken realities of gate keeping and controlling the space of scholarship publication. Suffices to conclude that it was his first year of editorial experience in the Journal of Public Administration published by the South African Association of Public Administration and Management (Sebola, 2018). Although peer review is the only available option of ensuring quality of published scholarly materials, Silbiger and Stubler (2019:1) attested that "quantitative evidence shows violations of objectivity and bias in the peer review process which affect the scholarship potential negatively". Indeed, as noted in Butchard, Rowberry, Squires and Tasker (2017:3)," peer review has grown into a monster" when talked about in scholarly publication. Not many authors view it in the positive light or rather a process that would help them to develop scholarly acumen in modern journal publication space. In modern academic or scholarly discourse, in as far as peer review is concerned, many view it as a brutal process where knowledge is only controlled by those in the editorial chairs and ensuring that all other descending views are not only kept to the minimum, but completely discarded from the scholarly publication and discussions. Thus far an impartial peer review practice which is expected in a scientific endeavour (Miller, Pevehouse, Rogohoski, Tingley and Wilson (2013) is not realisable in numerous scientific journals because of various pragmatic factors. Wilson (2012:1) noted "a crisis in peer review, where flawed papers are making it to print, leaked emails exchanges showing researchers trying to influence the process which leaves too little space for appropriate peer review". Indeed, in some journals only common names comes to the fore to dominate the publication concerned, while those emerging and unknown remain marginalised. At the worst some authors may appear twice in one journal volume and issue if sufficiently serving the interest of the editors.

\section{Developmental Scholarship}

The concept of a developmental scholarship is rarely talked of in academic circles in the context of research and development. However, many governments across the globe fund universities to pursue this mission in the research and development context to increase innovation, and not necessarily 
nurturing talent for development purposes. Literature that exists on developmental scholarship had inferred to an individual involved in teaching and learning while directing the process, and not necessarily directing research excellence. It is, however, notable that the original context of the concept scholarship had always referred to research excellency by scholars (Mirhoseini, Mehrdad, Bigdeli, Payravi and Khoddam, 2018). In this article, I am biased towards a developmental scholarship focussed on knowledge creation through research publication than teaching and learning. While the concept development scholarship does not really appear in any literature before or has not been academically conceptualised to be engaged about, there are academics (myself included) claiming that academic publications (Specifically journals) through editors need to adopt a developmental approach to nurture the talent of upcoming generation of researchers through a transparent system of peer review which aims at knowledge development than, the discouragement of it. The future of knowledge generation lies in the investment of the potential youth to carry and continue the future research innovation and development when the current ageing academics retire. The previous ageing academics have compromised quite a huge number of potential researchers to exists, hence creating a huge shortage of scholarship in the current academia.

The Association of Common Wealth Universities and Universities South Africa (2019) noted the "need for a next generation of teaching staff, of cutting- edge innovation and research leadership" as a valuable resource that need to be nurtured and developed. On other hand, Cloete and Blunting (2013:7) noted the importance of a university as to "produce a highly skilled and competent labour force, and in producing new knowledge". Although many believes that the developmental scholarship for research should be emphasised to build the next generation of scholars through the moulding at Masters and PHD level only, I believe that such potential is easily spotted and can be tapped from as early as at honours levels by academics who most of them are editors of scientific publications or directly or indirectly linked to editors of scientific publications. While I do acknowledge that the developmental approach to scholarship is pushed through the academia of formal qualification achievement by most university programmes, the editorial elites rarely discuss or openly explore such space to assist the youths in scholarship of writing. Moreover, the road to identifying early career academic is a difficult task to say the least (Lenyeo, Barkhuizen and Schutte, 2018). The notion of a pure developmental scholarship should aim at identifying strategies that will tap research potential at the earliest in which such talents are developed through research retreats and conference attendance. Scholarship engagements at that level improves creative minds of the youth. Often where government provided huge funding for academics and students development through conferences and research retreats for, such activities were either used for academic tourism with no accountability measures in place. Hence no development or production was achieved from such funds and those in authority took pride in reports for utilisation than on outputs achieved.

Many South African universities rarely explore the possibility of investing such potential in early research potential of the students. Moreover, (Lenyeo et al... (2018:1) noted that "the ability to attract quality young academics in academia remains a challenge for many south African universities". The failure to attract these young academics could be linked to our ability as academic institutions lacking a strategy to develop the youth for a scholarship path required of them. More often, those that we recruit are also frustrated to find that there are no proper mentorship programmes which prepares them for scholarship project path which the universities and government aspires them to be. On other hand Cloete, Maasen and Bailey (2015:135) found out that "a generally held view is that academics in African universities are relatively underpaid, and hence the low levels of (research) productivity". The former view explains often how difficult it is for an African academic to fully commit their time to mentoring the youth who will not be convinced to join the academic career. There is too much competition between the private sector, the public sector, and the universities to get the best produced employees. Such is despite an undeniable truth that Universities are the privileged spaces which provides space for the production and dissemination of knowledge (Cloete et al. 2015 ; Sebola, 2015). One would argue that if the Universities would have been doing enough to produce good human resource and knowledge dissemination as required of them, such function would not be difficult to attain. 


\section{Peer Review and the Effects on Developmental Scholarship}

Although peer review is currently the only system that can assure publishers of scientific journals that their articles passed through the scrutiny of high standards of their discipline and the control of dissemination of research data (Kelly, Sadeghieh and Adeli (2014:227), Sebola (2018) argued that the manner of peer review in some editorial space limit the production of new knowledge in research. That is likely to happen more on emerging scholars who are often not given a special consideration for a developmental talent. Indeed, peer review is used to filter quality from non-quality and at the same time ensuring that" unwarranted claims, unacceptable interpretations or personal views are not published without expert review (Kelly et al, (2015:227). However, Kelly et al... (2014:238-239) noted that there is no tested evidence to suggest that peer review indeed improves the quality of scientific work. There are indeed many articles which are peer reviewed and published with major grammatical, factual and ideological errors. When such articles are on the public space and noted, instead of them being put for scholarship review, scholars preferred to ignore them for use in their new materials. Scholars instead will engage on articles that are well written for critical review.

Generally, editors view peer review only in the three areas of editorial decision making which are ensuring that "a valid article is accepted, the messy article improved and the invalid article rejected" (Walker,2017). Thus far the focus has only been on valid article and messy article for publication. Very few editors, if any have ever looked for an option to look at the rejected article to see if it can be improved or not. Hence new authors in the field whose work were rejected with gross feedback never had an opportunity to think of writing again. This is even though reality has shown that the reviewers' taste of reading an article differs from one individual to the other. There are cases where an article is rejected by two blind reviewers of a low impact factor journal but get published without suggested corrections in a high impact factor journal. Such is an information or experience which has been tested by experienced authors, while novice authors are likely to discontinue writing than exploring an alternative option by sending to another journal when disappointed by the other. Peer review have not only disorientated experienced scholars in the field, but emerging researchers have been worse affected to further attempt their potential in scientific publications. The effects of peer review on developmental scholarship are a function of different aspects such as how editors handle their function of informing the scientific community and how the peer reviewers handle themselves in the review process. Some editors put the sole responsibility of a reviewed article to the reviewer, and reject it on that base without checking the validity of the reports themselves. The reviewers are human also and with limited knowledge and biasness most of the time. APA Science Student Council (2007:2) showed that" good reviews are thorough and balanced, highlighting both the limitations and strengths of the article". More often we only receive comments which are biased and limiting to knowledge production, which only focusses on the differing opinion with the reader and only indicating the biased limitations of the article.

\section{Good Practices in Peer Review}

The good practices in peer review are rooted on an assumption that published articles must undergo rigorous peer review process before publication. Therefore, a decision whether a manuscript is suitable for publication or not, should be subjected to peer review process to assess its scientific rigor, quality and credibility of scientific work by members of the disciplinary community (Tharirian and Sadri,2013). It is indeed important that peer review "filter out of the manuscript, irrelevant, trivial, misleading or potentially harmful content" (Kumar, 2009:1) so as to improve the quality of the material to be published. It is however, acknowledged in this area of argument that some journals do peer review (Armstrong, 1982; Sebola,2018), while others do not do peer review at all. There are editors who compromise peer review and forget that "peer review is the basis of the respectability and authority of science, it should be mandatory; and that it should be as flawless as possible" (Kumar, 2009:4). Articles with questionable scientific assumptions, harmful content continue to receive 
publication status in some journals claiming to be extensively peer reviewed. Well established and self-acclaimed credible journals are likely to bypass the review process because the names of their editors and journals speaks for themselves. The University of Cape Town in South Africa, despite its scientific credibility has two recent cases where the University must distance itself from researchers who published harmful content under the auspices of their institution. Safe to say such publications were not from predatory and it happened despite the editorial guidelines of same journals claiming to guard against the same. When such editorial mishaps occur, only the author and the university research ethics are at the core of criticism, while the editor who should take the blame take a back seat. Depending on the credibility of the journals, different types of peer review can be followed by the journal concerned. Single and blind peer review are the most common and widely used in modern journals to get scientific credibility (EditorResources, n. d:3). Single blind peer review and open peer review are normally practiced by highly influential journals and editors (Sebola, 2018). Academy of Science of South Africa has recommended triple blind review to improve the quality (Sebola,2018) of article publication by South African journals, while journals like the Corntree journal published by North West University recommended quadruple blind review. While such practice may be viewed as improving quality by some, it may also result in contradicting improvements suggested to the author. Although good peer review practice seems to lean more highly on blind peer review, such is also dependent on the following: Who decides on publication of an article? The instruments of peer review and who are the experts?

Who decides on publication of article?

Generally, it is believed that the editor decides on the publishability of the article based on the reviewers' reports (Lasker, 2018), especially about "what fit with the journal, the publishers existing output, the size of the likely market and literary style" (Fyfe, Coate, Curry, Lawson, Moxhom, and Rostvik (2017). Such is because we believe that peer reviewers provide experts advice on the quality of the work to be published. However, the reality is that often editors may ignore the peer reviewers' judgement on the article and publish it otherwise if he or she so feels. In some journals, guidelines clearly state that "the editor reserves the right to accept or reject an article even if accepted or rejected by peer reviewers". This right which is unknown to many authors often result into "elitist culture" in publication where an editor and his elite group control publication according to their philosophy, in which reviewers tend to be respected authors in the same field and only tend to agree with authors whose conclusions are similar to theirs and disagree with authors whose conclusions contradict their believes (Kumar,2009:3)". Some editors only subject an article to peer review when they want it published than getting objective opinions from reviewers, while such act genuinely compromise the purpose of the peer review process. A good peer review is open, transparent and consistent.

\subsection{The instruments of peer review}

Good peer review mechanism is likely to be ensured through peer review instruments which will provide learning to the authors. Thus far journals use different instruments of evaluation for peer review which most of them provide little learning to the authors. Some journals use evaluation instruments which only requires peer reviewers to evaluate on a scale of 1-10. Such instruments provide no space for detailed narrative report which authors may learn from the reviewed article. Some reviewers may like such journals because they safe them time to crack their head on writing detailed narrative reviews. Some journals only provide evaluation instruments which only provide for yes or no responses, which also provide little learning space for the author. It is recommended that even if scales of yes or no can be used to evaluate a peer reviewed article, a space for a detailed narrative report is required to provide authors with a learning experience of what the reviewers are trying to convey to them in the improvement or reconstruction of the article. Some reviewers enjoy just to tick boxes to accept or reject an article without justification. 


\subsection{Who are the experts?}

The rule of thumb in scientific publication is that scholarly publication should be scientifically subjected to expertise knowledge in the discipline concerned (Miller, Prevehouse, Rogowski, Tingley and Wilson, 2013). It can, however, be argued that some journals have not used specialised expertise in publication of discipline specific journals which ended in scientific flaws characterised by invalid assumptions and factual errors. Alleoni (2014:2) noted that due to factors beyond capacity of editors "in finding good peer reviewers, professionals without proper experience and skills are invited to evaluate manuscript". Yaddanapudi and Yaddanapudi (2015), acknowledged that peer reviewers do not necessarily need to be authorities in the subject, but need to be familiar with the domain of the manuscript. While such has proved to be acceptable in other scientific publications, this has proved to be a weakness in peer review in the sense that often individuals from an extreme opposite subject matter are used to evaluate manuscript which are not in their line of science. Some journals will send an article on robotics for an evaluator in the discipline of Public Administration and expecting such reviewer to do justice to the reviewed manuscript. Despite being in the discipline or not, some journals will invite a reviewer simply because he once sent a manuscript to their journal irrespective of whether it fits the scope or not. Indeed, as others have argued" peer review has showed to be in crisis as "scientists face strong incentive to submit papers, but little incentive to review" (House of Commons, 2011:45). The desire to publish has become significant in academia, to the extent that those who need to be published in journals do not want to review other scientists work, resulting in too much publication backlogs in other journals.

\section{Conclusion}

The article captured numerous flaws regarding the peer review practices in South African journal publication environment and its failure to nurture young scholarship talents. It is sufficient to conclude that good review practices are be adopted and maintained in a consistent manner. While not all journals need to be painted on a similar brush when it comes to compromised peer review practices, literature shows that most journals have not sufficiently explored positively the practice of good peer review practices. More often the challenges of peer review such as reviewers failing to provide feedback could have been brushed aside by editors who by virtue of their credibility and experience continuing to publish an article. It is an undisputable truth that experienced editors and their journals are above the requirements of peer review. Such editors and journals have already established a strong network of readership and authors and therefore can determine an article worth to be read by their readers than to be determined by the reviewer.

\section{Refferences}

Alleoni, A. 2014. The role of peer review. Arquivos do Instituto Biológico. São Paulo, 81: 1-2.

APA Science Student Council. 2007. A graduate students's guide to involvement in the peer review process. Washington DC: APA Science Student Council

Armstrong, J. S. 1982. Research on scientific journals: implications for editors and authors. Journal of forecasting, 1 (1):83-104.

Butchard, D., Rowberry, S., Squires, C. \& Tasker, G. 2017. Peer review in practice. In: Rayner S, Lyons R (ed.). Academic Book of the Future. London: UCL Press.

Cloete, N. \& Blunting, I. 2013. Strengthening knowledge production in universities: five south African case studies. Paris: Organisation for Economic Co-operation and Development

Cloete, N., Maasen, P. \& Bailey, T. 2015. Knowledge production and contracdictory functions in African Higher education. Cape Town: African Minds.

Fyfe, A., Coate, K., Curry, S., Lawson, S., Moxhom, N. \& Rostvik, C.M. 2017.Untangling academic publishing: a history of the relationship between commercial interest, academic prestige and the circulation of research. Geneva: Zenoda 
House of Commons. 2011. Peer review in scientific publications: eight report of session 2010-2012. London: House of Commons.

Kelly, J., Sadeghieh, T. and Adeli, k. 2014. Peer review in scientific publications: benefits, critiques \& a survival guide. Journal of The International Federation Of Clinical Chemistry And Laboratory Medicine,25(3):227243.

Kumar, M. 2009. A review of the review process: manuscript peer-review in biomedical research. Biology and Medicine, 1(4):1-16.

Lasker, S. 2018. Peer Review system: A Systematic Review. Bangladesh Journal of Bioethics, 9 (13):13-23.

Lenyeo, D.L., Barkhuizen, N.E. and Schutte, N.E. 2018. Factors relating to the attraction of talented early career academics in South African higher education institutions. SA Journal of Human Resource Management, 16(o):1-10.

Maserumule, M.H. 2012. Meaning of editorship and the unanswered question of the discipline - editorial essay. Journal of Public Administration, 47(3): 605-617.

Miller, B., Prevehouse, J., Rogowski, R., Tingley, D. and Wilson, R. 2013. How to be a peer reviewer: A guide for recent and soon-to-be- PhDS. Political Science \& Politics, 46(1): 120-123.

Mirhoseini, Mehrdad, Bigdeli, Payravi \& Khoddam. 2018.

Sebola, M. P. 2018. Peer review, scholarship and editors of scientific publications: The death of scientific knowledge in Africa. Koers, 83(1):1-13.

Silbiger, N. J. \& Stubler, A. D. 2019. Unprofessional peer reviews disproportionately harm underrepresented groups in STEM. PeerJ 7:1-14.

Tharirian, M.H. and Sadri, E. 2013. Peer reviewers's comments on research articles submitted by Iranian researchers. Journal of teaching language skills, 5(3):107-123.

The Association of Common Wealth Universities and Universities South Africa. 2019. Generating talent: Transforming support for the research landscape in South Africa. London: The Association of Common Wealth Universities and Universities South Africa

Walker, M.D. 2017. Reviewing a journal article (peer review). Boston: Division of developmental medicine

Wilson, J. 2012. Standing up for science 3: Peer review, the nuts and bolts. A guide for early career researchers. London: Sense about science.

Yaddanapudi and Yaddanapudi. 2015. An introduction to peer review. Journal of anaesthesiology clinical pharmacology, 31(4):437-439. 